\title{
Feohifomicosis nasal por Curvularia spicifera en un paciente pediátrico con neutropenia y leucemia mieloide aguda
}

\author{
Constanza Bay, Tamara González, Gonzalo Muñoz, Paulette Legarraga, Cecilia Vizcaya y Katia Abarca
}

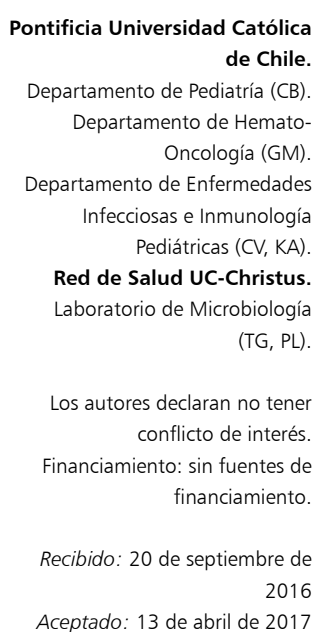

Correspondencia a: Katia Abarca V. katia@med.puc.cl

\section{Introducción}

L as infecciones causadas por hongos filamentosos dematiáceos, caracterizados por formar colonias oscuras e hifas septadas o elementos levaduriformes con pared oscura, son conocidas como feohifomicosis. El color característico de este grupo está relacionado con la presencia de melanina, la cual se cree que podría ser un importante factor de virulencia. Más de 100 especies fúngicas han sido documentadas como agentes de feohifomicosis, incluidos los géneros Alternaria, Bipolaris, Curvularia, Exophiala y Scedosporium $\mathrm{spp}^{1-3}$.

El género Curvularia incluye más de 80 especies, de las cuales la mayoría se encuentran en la tierra, plantas y materia inorgánica ${ }^{4-6}$. Su distribución es mundial, pero se ha reportado principalmente en regiones tropicales y subtropicales ${ }^{7}$, asociado a diferentes tipos de infecciones, tales como queratitis y úlceras corneales ${ }^{8}$, sinusitis $^{9-12}$, micetoma $^{13}$, infecciones cutáneas y subcutáneas ${ }^{14-16}$, peritonitis asociada a diálisis ${ }^{17,18}$, endarteritis ${ }^{19}$, absceso cerebral $^{19,20}$, meningitis y encefalitis ${ }^{21,22}$, alergia broncopulmonar $^{18,23,24}$ e infecciones diseminadas ${ }^{24-26}$. Curvularia spp. es capaz de infectar personas sanas y pacientes inmunocomprometidos ${ }^{18}$. No se conoce la real incidencia de las diferentes especies de Curvularia en seres humanos, existiendo comunicaciones de casos de infecciones principalmente en adultos, y muy infrecuentes en la población pediátrica $^{18,27}$. La información sobre el tratamiento de estas infecciones también es escasa, sin haberse definido la terapia más apropiada ${ }^{1,28,29}$. El objetivo de esta publica- ción es presentar un caso de una infección fúngica poco frecuente en niños y revisar los casos que existen de ésta en la literatura científica. Con ello se pretende contribuir al diagnóstico diferencial de las infecciones fúngicas en pacientes de alto riesgo.

\section{Caso clínico}

Escolar de sexo masculino con 8 años de edad, residente en Santiago, con antecedentes de una leucemia mieloide aguda (LMA) M4, sometido a un trasplante de precursores hematopoyéticos (TPH) un año antes y rinitis alérgica. Evolucionó con una recaída de su leucemia tras lo cual se administró un ciclo de quimioterapia en preparación a un nuevo TPH. Ocho días después se hospitalizó por un episodio de neutropenia febril, por lo que se inició vancomicina, ceftazidima y amikacina. Refirió dolor en la fosa nasal derecha e incisivo superior, constatándose cuatro días después de su ingreso, una erosión leve en la fosa nasal derecha (FND) con signos de sangrado reciente y una costra dolorosa en la porción antero-inferior del tabique nasal izquierdo (FNI). Esta última se removió y se envió a cultivo bacteriano y de hongos. Bajo la costra se observó una lesión del cartílago septal más adherida y negruzca, cuya superficie se removió sin presentar sangrado. Se envió a tinción de calcoflúor, la cual evidenció hifas septadas por lo que se inició voriconazol iv $9 \mathrm{mg}$ / $\mathrm{kg} /$ dosis, dos veces al día. La tomografía computarizada (TC) de cavidades paranasales evidenció cambios inflamatorios pansinusales sin extensión extrasinusal (Figu- 

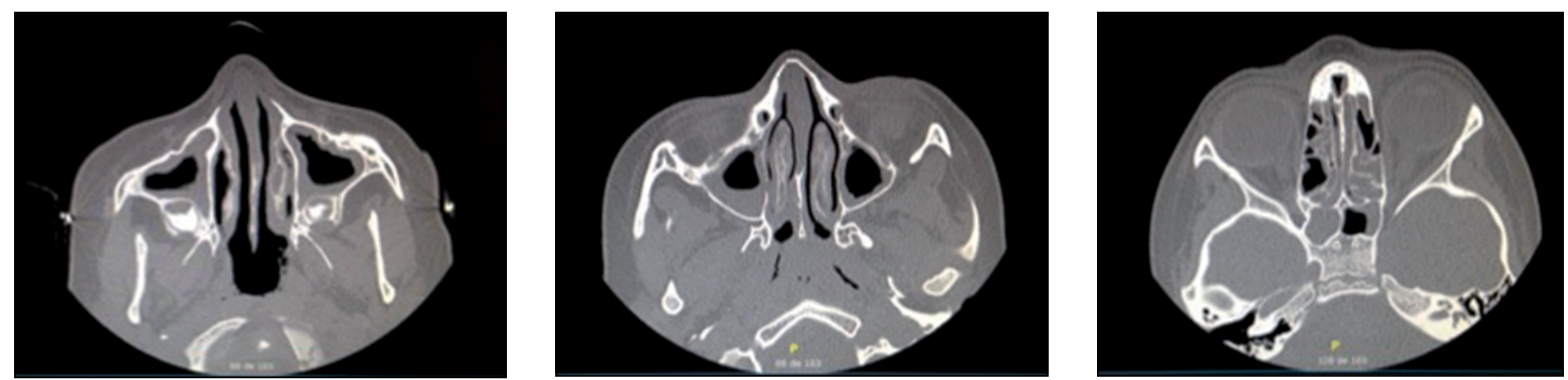

Figura 1 a, b, c. Tomografía axial computarizada de senos paranasales, cortes transversales. Hallazgos: cambios inflamatorios pansinusales, con engrosamiento mucoso de ambos senos maxilares y senos frontales. Celdillas etmoidales y seno esfenoidal derecho ocupados por secreciones. Infundíbulos de los complejos ostiomeatales obliterados por engrosamiento mucoso. No hay signos de osteólisis en las paredes de los senos paranasales, ni evidencia de extensión extrasinusal.

ra 1). Se realizó precozmente una cirugía endoscópica nasal, consistente en una esfenoidotomía derecha, con resección de tabique nasal necrótico y del cartílago septal izquierdo. Se enviaron muestras de cornete superior y esfenoides derecho, mucosa de tabique nasal y cartílago septal izquierdo a biopsia. Las dos primeras se enviaron además a tinción de calcoflúor resultando negativas y a cultivo bacteriano. Las muestras fueron sembradas en agar Sabouraud dextrosa a temperatura ambiente y a $35^{\circ} \mathrm{C}$.

La muestra quirúrgica de tabique nasal y la de cartílago septal mostraron a las $48 \mathrm{~h}$ desarrollo de colonias de 4-6 $\mathrm{mm}$, algodonosas, laxas con aspecto de polvo de hollín, de color blanco grisáceo, y color oliváceo por el reverso (Figura 2). La muestra del esfenoides derecho fue negativa. A la microscopia se observaron hifas dematiáceas, con conidióforos color café claro, septados, solitarios y geniculados, zigzageantes en la región apical, desde donde brotaban conidios de forma simpodial. Éstos eran color marrón, cilíndricos, de paredes pigmentadas gruesas, con tres distoseptos y cuatro células, con cicatrices de color marrón oscuro en el lugar de unión a la hifa conidiogénica (Figura 3). Basados en la macroscopia y microscopia se identificó el agente como una Curvularia spicifera. Para confirmación de género, se realizó una reacción de polimerasa en cadena (RPC) universal y posterior secuenciación de los segmentos génicos ITS1, ITS4 y 5,6S ARNr, a las colonias desarrolladas, identificándose Curvularia spp.

La biopsia de la mucosa del tabique nasal y del cartílago septal izquierdo mostró extensas zonas de destrucción, necrosis, ulceración y hemorragia asociadas a la presencia de abundantes elementos micóticos filamentosos histo y angioinvasores. Los elementos micóticos correspondían a filamentos hialinos tabicados con algunas dilataciones globosas y crecimiento variable de $45^{\circ}$ a $90^{\circ}$, con caracteres de hialohifomicetes. La

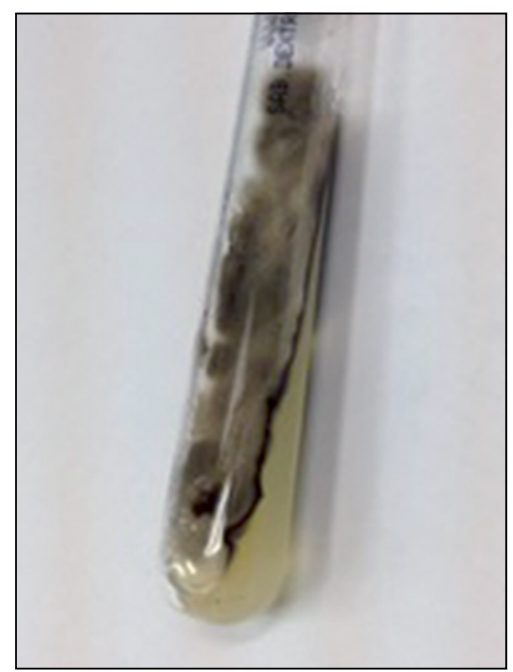

Figura 2. Cultivo agar Sabouraud dextrosa con crecimiento de colonias algodonosas grisáceas.

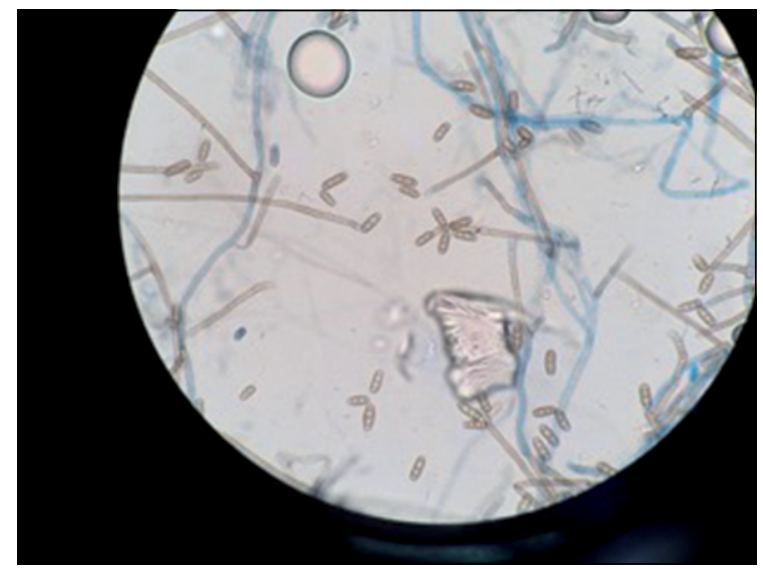

Figura 3. Microscopía óptica directa (100x) evidencia hifas dematiáceas compatibles con Curvularia spicifera. 
muestra de pared ósteo-condro-mucosa de cornete y esfenoides derecho sólo mostró signos de inflamación crónica activa inespecífica.

Para el estudio de sensibilidad antifúngica las colonias obtenidas en agar Sabouraud fueron sembradas en agar agua para aumentar la producción de conidias. Se realizó micro dilución según la norma CLSI, documento M38-A2, resultando sensible a los tres antifúngicos estudiados, con CIM a anfotericina B de $1 \mu \mathrm{g} / \mathrm{ml}$, posaconazol $0,25 \mu \mathrm{g} /$ $\mathrm{ml}$ y voriconazol $0,25 \mu \mathrm{g} / \mathrm{ml}$.

Tras la identificación etiológica, se ajustó el esquema antifúngico asociando anfotericina liposomal $5 \mathrm{mg} / \mathrm{kg} /$ día y se realizó un nuevo aseo quirúrgico dos días después, observándose la mucosa nasal sin necrosis, con tinción de calcoflúor y cultivo negativos. Las detecciones de galactomanano en sangre se mantuvieron negativas durante la evolución. Recibió voriconazol por 40 días, con concentraciones plasmáticas variables entre $0,2-1,6 \mathrm{mg} / \mathrm{L}$ (rango terapéutico 1-5 mg/L) y anfotericina liposomal por 25 días (dosis acumulada $125 \mathrm{mg} / \mathrm{kg}$ ). Evolucionó en forma satisfactoria del punto de vista otorrinológico. Recibió un segundo TPH, sin presentar lesiones cutáneas ni síntomas nasales en los siguientes meses. Sin embargo, no logró reconstitución inmune, falleciendo por otras complicaciones infecciosas.

\section{Discusión}

En los últimos años, la incidencia de infecciones invasoras por hongos dematiáceos ha aumentado significativamente, muy probablemente en relación al aumento de pacientes inmunocomprometidos. La feohifomicosis ha sido cada vez más reportada en inmunocomprometidos, pacientes receptores de trasplante de órganos sólidos, con neoplasias hematológicas, aquellos que reciben corticosteroides, entre otros, por lo que se considera como una micosis emergente en estos grupos de pacientes ${ }^{1}$. En un centro de cáncer se reportó un aumento de la incidencia de 1 a 3,1 casos por 100.000 pacientes-días durante un período de 19 años ${ }^{30}$.

Las feohifomicosis cutáneas y de tejidos blandos pueden ser causadas por múltiples especies diferentes de hongos dematiáceos y pueden ser infecciones superficiales cutáneas, corneales, subcutáneas o sistémicas. Las infecciones cutáneas asociadas con C. spicifera han sido reportadas en forma de abscesos, nódulos subcutáneos, úlceras persistentes y lesiones induradas que evolucionan a úlceras necróticas ${ }^{1,15,25-27}$. También, se ha descrito la progresión de una lesión cutánea a una infección diseminada en tratamientos tardíos ${ }^{14}$.

En este caso, se describe una feohifomicosis nasal, donde a pesar de haber hallazgos de inflamación pansinusal no hubo evidencia de infección fúngica sinusal. El compromiso fúngico de los senos nasales es una de las localizaciones más frecuentes y comúnmente se presenta en individuos con rinitis alérgica y/o pólipos nasales. Se han identificado cuatro formas clínicas: indolente, alérgica, micetoma e invasora. La forma invasora es la más grave, pues puede ser de evolución rápidamente agresiva, especialmente en inmunocomprometidos. Las micosis sinusales pueden extenderse a estructuras contiguas y generar complicaciones graves, como invasión orbitaria y más grave aún, invasión intracraneal, pudiendo amenazar la vida. Existen varios reportes de encefalitis granulomatosa y feohifomicosis cerebral por C. spicifera $^{20-22}$. La trombosis de senos cavernosos y los abscesos fúngicos cerebrales son usualmente refractarios al manejo médico e intervenciones quirúrgicas ${ }^{31-33}$.

El tratamiento de las infecciones fúngicas invasoras, principalmente en inmunocomprometidos, constituye aún un desafío, ya que no se ha logrado establecer cuál es la terapia antifúngica óptima ${ }^{31,34}$. El manejo inicial de las lesiones cutáneas involucra el desbridamiento quirúrgico agresivo con márgenes libres. En general, las feohifomicosis localmente invasoras tienden a responder a un amplio rango de agentes antifúngicos ${ }^{1,32,35}$. Las infecciones diseminadas pueden ser fatales, por lo que es imperativo el diagnóstico precoz y definir su extensión para el rápido inicio de la terapia ${ }^{25,26}$. En estos casos, el tratamiento se basa en la terapia antifúngica sistémica, tradicionalmente con anfotericina $\mathrm{B}$, en algunos casos en conjunto con azoles $^{25,35}$. Tratamientos con itraconazol han mostrado resultados positivos ${ }^{33}$. La sensibilidad in vitro no siempre predice una respuesta clínica favorable ${ }^{9,26}$. Un estudio de susceptibilidad in vitro de 99 aislados de Curvularia spp. mostró mayor sensibilidad a las equinocandinas, anfotericina B y posaconazol, en cambio voriconazol e itraconazol mostraron poca actividad ${ }^{31}$. Por otra parte, en algunos casos el desbridamiento quirúrgico precoz e irrigación sinusal por sí solos han sido efectivos en el manejo de sinusitis fúngicas ${ }^{12}$. Como es posible concluir, el tratamiento de elección no es claro, pero sí parece ser dependiente de la extensión de la infección y del estado inmune del paciente. En el presente caso, la inmunidad del paciente estaba comprometida y además la biopsia de mucosa y cornete nasal mostró evidencias de histo y angioinvasión, razones por las cuales la terapia incluyó aseo quirúrgico y se mantuvo con terapia antifúngica sistémica biasociada por un tiempo prolongado.

La taxonomía de estos hongos ha experimentado importantes cambios en los últimos años. Los géneros Cochliobolus, Bipolaris y Curvularia forman un complejo que contiene muchas especies de distribución mundial. No existe un límite claro respecto a la morfología entre los géneros Bipolaris y Curvularia, y algunas especies tienen morfología intermedia. La especie Bipolaris spicifera, previamente identificada como Drechslera spicifera ${ }^{36}$, 
fue recientemente transferida al género Curvularia en una actualización taxonómica realizada por Manamgoda y cols., en 2012 denominándose actualmente $C$. spicifera ${ }^{4}$. La primera infección por la entonces llamada $D$. spicifera fue reportada en 1977 en un paciente pediátrico inmunocomprometido ${ }^{15}$. El análisis genético combinado de rDNA ITS (espaciador interno transcrito), GPDH (gliceraldehído 3-fosfato deshidrogenasa), LSU (subunidad larga) y EF1- $\alpha$ (factor 1- $\alpha$ de elongación de la traducción) concluyó que este complejo grupo genérico se divide en dos grupos, las especies Bipolaris y Cochliobolus, agrupados en el grupo Bipolaris, y las especies de Curvularia agrupadas en otro ${ }^{4}$. Desde el reciente cambio taxonómico no existen reportes de infecciones por $C$. spicifera en niños, siendo a nuestro conocimiento éste el primero.

Las especies de Curvularia se caracterizan microscópicamente por colonias algodonosas color café oscuro a negro, con micelios oscuros, conidióforas geniculadas con curvaturas en las zonas de origen de las conidias y ramificación simpodial. Las conidias son elongadas, de paredes lisas a trabeculadas, con cuatro células, múltiples falsos septos (distoseptos) los cuales pueden ser derechos o curvos, y cuatro células con una célula central más grande y generalmente más oscura ${ }^{5,37,38}$. Al comparar los géneros Curvularia y Bipolaris se observa que los primeros tienden a tener conidias más cortas (en la mayoría de las especies menor a $100 \mu \mathrm{m}$ ) y son usualmente rectos o curvos; los curvos tienen células intermedias más grandes lo cual contribuye a su curvatura. Las conidias de las especies Bipolaris son usualmente más largas y separadas que las de Curvularia (usualmente mayores a $100 \mu \mathrm{m}$ ) y pueden ser rectas o levemente curvas ${ }^{4,39,40}$.

Existen escasas comunicaciones de infecciones por Curvularia spp. en niños. La búsqueda en la literatura especializada mostró 11 casos pediátricos (menores de 18 años) de infección por B. spicifera (Tabla 1), involucrando distintos sitios y sistemas. Cuatro casos ocurrieron en pacientes inmunocomprometidos, de los cuales dos tuvieron infección fúngica diseminada ${ }^{25,26}$ y los otros dos, infecciones cutáneas localizadas ${ }^{15,16}$. En todos los casos el diagnóstico se confirmó por histopatología, microscopia y/o cultivos de muestras de fluidos corporales, secreciones o tejidos obtenidos por biopsia. Adicionalmente, en un caso se reportó la evaluación post-mortem con demostración histológica compatible con una infección fúngica diseminada. Ocho pacientes recibieron terapia antifúngica, los dos pacientes con infecciones diseminadas fallecieron a pesar del tratamiento ${ }^{25,26}$ y el resto tuvo buena respuesta. En un caso se reportó una recurrencia a pesar de la terapia y posterior mejoría sintomática, pero sin resolución completa y con cultivos persistentemente positivos ${ }^{22}$. Los tres pacientes que no recibieron antifúngicos presentaron sinusitis que se manejaron de forma quirúrgica con buena respuesta ${ }^{10,11}$. Sin embargo, uno de ellos tuvo una recurrencia que requirió cirugía y antifúngicos ${ }^{11}$. De los 10 pacientes que recibieron tratamiento médico, en nueve de ellos el agente antifúngico inicial de elección fue anfotericina B, en un caso se usó fluconazol ${ }^{17}$. Fuera de los casos mencionados en la Tabla 1, en una serie de 21 casos de infección por Bipolaris en pacientes con cirugía cardiotorácica hubo cinco niños, de éstos dos en menores de un año; sin embargo, no se hace referencia a la especie involucrada en cada caso. Se menciona que en los casos en que se logró identificación de la especie, $75 \%$ fue por B. spicifera $^{36}$. Además, Sobol y cols., comunicaron un caso de un niño inmunocompetente con una osteomielitis por $D$. spicifera que evolucionó con múltiples abscesos cerebrales metastásicos ${ }^{19}$.

Nuestro caso, de una infección nasal invasora por $C$. spicifera, tras desbridamiento quirúrgico precoz y repetido, con tratamiento antifúngico bi-asociado logró una resolución completa de las lesiones. No se encontraron hallazgos clínicos, radiológicos ni microbiológicos sugerentes de infección diseminada. La resolución exitosa de la infección podría atribuirse al manejo terapéutico precoz y agresivo y a la ausencia de compromiso fúngico sinusal y de extensión ósea o cerebral. Probablemente el desbridamiento quirúrgico eliminó todo el tejido infectado y el tratamiento precoz con voriconazol y anfotericina liposomal erradicó los microorganismos restantes. Dado que existen casos con resolución favorable sin terapia antifúngica, es difícil concluir si el manejo antimicrobiano es realmente beneficioso o no. Es probable que en algunos casos el mismo sistema inmune sea capaz de controlar la infección. Sin embargo, en hospederos inmunocomprometidos las infecciones fúngicas oportunistas representan una real amenaza, pues las infecciones primarias pueden diseminarse rápidamente y ser de riesgo vital. Esto hace que un manejo diagnóstico y terapéutico agresivo sea fuertemente recomendado en estos casos.

Cabe destacar que en este paciente no se evidenciaron hongos pigmentados en el estudio histopatológico. Sin embargo, la infección se interpretó como una feohifomicosis y se manejó como tal. Para el diagnóstico de una infección fúngica se requiere de cultivos y del estudio histopatológico de los tejidos. Sin embargo, los hongos dematiáceos no son fáciles de cultivar ni de identificar, y son causa frecuente de contaminación de laboratorio, por lo que su diagnóstico puede ser un desafío. En un estudio de micosis de la piel se reportó una sensibilidad de $85 \%$ para la detección de elementos fúngicos en el estudio histopatológico, el cual aumentó a $100 \%$ aplicando la tinción plata metenamina de Gomori ${ }^{41}$. En una revisión del diagnóstico histopatológico de las infecciones fúngicas se explica que a pesar de que todos los hongos dematiáceos muestran hifas pigmentadas, la intensidad de la pigmentación puede variar ${ }^{42}$. Por ende, es posible que las hifas se hayan visto hialinas si es que 


\begin{tabular}{|c|c|c|c|c|c|c|c|c|c|c|}
\hline $\begin{array}{l}\text { Lugar } \\
\text { (hospital, } \\
\text { país, año) }\end{array}$ & $\begin{array}{l}\text { Paciente } \\
\text { (edad, } \\
\text { sexo) }\end{array}$ & $\begin{array}{l}\text { Antecedentes } \\
\text { médicos }\end{array}$ & Diagnóstico & $\begin{array}{l}\text { Agente } \\
\text { etiológico }\end{array}$ & $\begin{array}{c}\text { Sitios } \\
\text { involucrados }\end{array}$ & Estudio & Antifúngicos & $\underset{(\mu \mathrm{g} / \mathrm{ml})}{\mathrm{CIM}}$ & Resultado & $\begin{array}{l}\text { Refe- } \\
\text { rencia }\end{array}$ \\
\hline $\begin{array}{l}\text { Johns Hopkins } \\
\text { Hospital, } \\
\text { Baltimore, } \\
\text { E.U.A, } 1975\end{array}$ & $\begin{array}{c}5 \text { años, } \\
\text { M }\end{array}$ & $\begin{array}{l}\text { Leucemia linfo- } \\
\text { blástica aguda, } \\
\text { quimioterapia }\end{array}$ & $\begin{array}{l}\text { Feohifomicosis } \\
\text { cutánea }\end{array}$ & $\begin{array}{l}\text { Drechslera } \\
\text { spicifera }\end{array}$ & $\begin{array}{l}\text { Piel antebrazo } \\
\text { izquierdo }\end{array}$ & $\begin{array}{l}\text { Biopsia excisional } \\
\text { piel y superficie: mi- } \\
\text { croscopia + histopa- } \\
\text { tología + cultivos }\end{array}$ & $\begin{array}{l}\text { AMB iv } \\
\text { por } 8 \text { días }\end{array}$ & $\begin{array}{c}\text { AMB } \\
<0,05 \\
\text { Flucitosina } \\
0,8\end{array}$ & Sobrevive & $(15)$ \\
\hline $\begin{array}{l}\text { Oklahoma } \\
\text { Children's } \\
\text { Memorial } \\
\text { Hospital, } \\
\text { E.U.A, } 1983\end{array}$ & $\begin{array}{c}10 \text { años, } \\
\text { M }\end{array}$ & Ninguno & $\begin{array}{l}\text { Feohifomi- } \\
\text { cosis de los } \\
\text { senos maxilar } \\
\text { y etmoidal } \\
\text { izquierdos }\end{array}$ & $\begin{array}{l}\text { Drechslera } \\
\text { spicifera }\end{array}$ & $\begin{array}{l}\text { Senos maxilar } \\
\text { y etmoidal } \\
\text { izquierdos }\end{array}$ & $\begin{array}{c}\text { Secreciones y tejido } \\
\text { sinusal: microscopia } \\
+ \text { histopatología }+ \\
\text { cultivos }\end{array}$ & $\begin{array}{l}\text { No recibió } \\
\text { inicialmen- } \\
\text { te. AMB en } \\
\text { irrigaciones } \\
\text { nasales }\end{array}$ & $\begin{array}{l}\text { Sensible } \\
\text { a AMB e } \\
\text { imidazoles } \\
\text { (CIM no } \\
\text { reportadas) }\end{array}$ & $\begin{array}{l}\text { Sobrevive. Re- } \\
\text { currencia tras } \\
\text { publicación }\end{array}$ & (11) \\
\hline $\begin{array}{l}\text { Oklahoma } \\
\text { Children's } \\
\text { Memorial } \\
\text { Hospital, } \\
\text { E.U.A, } 1983\end{array}$ & $\begin{array}{c}12 \text { años, } \\
F\end{array}$ & Ninguno & $\begin{array}{l}\text { Feohifomi- } \\
\text { cosis de los } \\
\text { senos maxilar } \\
\text { y etmoidal } \\
\text { izquierdos }\end{array}$ & $\begin{array}{l}\text { Drechslera } \\
\text { spicifera }\end{array}$ & $\begin{array}{l}\text { Senos maxilar } \\
\text { y etmoidal } \\
\text { izquierdos }\end{array}$ & $\begin{array}{l}\text { Secreciones y tejido } \\
\text { sinusal: microscopia } \\
+ \text { histopatología + } \\
\text { cultivos }\end{array}$ & No recibió & $\begin{array}{l}\text { Sensible } \\
\text { a AMB e } \\
\text { imidazoles } \\
\text { (CIM no } \\
\text { reportadas) }\end{array}$ & $\begin{array}{l}\text { Sobrevive, } \\
\text { asintomática } \\
9 \text { meses } \\
\text { postopera- } \\
\text { torio }\end{array}$ & (11) \\
\hline $\begin{array}{l}\text { UCLA Medical } \\
\text { Center, LA, } \\
\text { E.U.A, } \\
\text { 1983-1986 }\end{array}$ & $\begin{array}{c}7 \text { años, } \\
\text { F }\end{array}$ & $\begin{array}{l}\text { Rinitis alérgica, } \\
\text { Hipersensibilidad } \\
\text { cutánea }\end{array}$ & $\begin{array}{l}\text { Sinusitis } \\
\text { recurrente }\end{array}$ & $\begin{array}{l}\text { Bipolaris } \\
\text { spicifera }\end{array}$ & $\begin{array}{l}\text { Senos maxilar, } \\
\text { frontal, etmoi- } \\
\text { dal y esfenoidal } \\
\text { derechos }\end{array}$ & $\begin{array}{l}\text { Secreciones + tejido } \\
\text { sinusal: microscopia } \\
\quad+\text { cultivos }\end{array}$ & $\begin{array}{l}\text { AMB por } 4 \\
\text { meses. Luego } \\
\text { AMB } 10 \text { días, } \\
\text { cambio a KTC } \\
\text { y luego ITR } \\
\text { completó } 8 \\
\text { meses }\end{array}$ & $\begin{array}{l}\text { AMB 1,0, } \\
\text { MIC } 0,5, \\
\text { Flucitosina } \\
100 \\
\text { KTC } 12,5\end{array}$ & $\begin{array}{l}\text { Sobrevive. } \\
\text { Recurrencia } \\
\text { tras } 15 \\
\text { meses }\end{array}$ & $(12)$ \\
\hline $\begin{array}{l}\text { San Antonio, } \\
\text { Texas, E.U.A, } \\
1987\end{array}$ & $\begin{array}{c}16 \text { años, } \\
\text { F }\end{array}$ & $\begin{array}{l}\text { Asma extrínseco, } \\
\text { Inmunoterapia }\end{array}$ & $\begin{array}{l}\text { Pansinusitis, } \\
\text { pólipos nasales }\end{array}$ & $\begin{array}{l}\text { Bipolaris } \\
\text { spicifera }\end{array}$ & $\begin{array}{l}\text { Todos los senos } \\
\text { nasales }\end{array}$ & $\begin{array}{c}\text { Secreciones sinusa- } \\
\text { les: microscopia + } \\
\text { histopatología + } \\
\text { cultivos. } \\
\text { Prick test } \\
\text { IgE específica }\end{array}$ & No recibió & $\begin{array}{c}\text { No } \\
\text { reportado }\end{array}$ & $\begin{array}{l}\text { Sobrevive, } \\
\text { asintomática } \\
9 \text { meses } \\
\text { postopera- } \\
\text { torio }\end{array}$ & (10) \\
\hline $\begin{array}{l}\text { St Thomas } \\
\text { Hospital, } \\
\text { Nashville, } \\
\text { Tennessee, } \\
\text { E.U.A, } 1999\end{array}$ & $\begin{array}{c}18 \text { años, } \\
\text { M }\end{array}$ & Neuroma acústico & $\begin{array}{l}\text { Meningitis } \\
\text { fúngica } \\
\text { nosocomial }\end{array}$ & $\begin{array}{l}\text { Bipolaris } \\
\text { spicifera }\end{array}$ & SNC & LCR: cultivos & $\begin{array}{l}\text { AMB (ev + } \\
\text { intratecal) } \\
\text { duración no } \\
\text { especificada }\end{array}$ & $\begin{array}{c}\text { AMB } 0,25 \\
\text { Flucitosina } \\
>64 \\
\text { FLC } 64 \\
\text { ITR } 0,125\end{array}$ & $\begin{array}{l}\text { Sobrevive, en } \\
\text { rehabilitación } \\
\text { a } 1 \text { año }\end{array}$ & (23) \\
\hline $\begin{array}{l}\text { San Antonio, } \\
\text { Texas, E.U.A, } \\
2001\end{array}$ & 7 días & $\begin{array}{l}\text { Pretérmino } 23 \\
\text { semanas, bajo } \\
\text { peso, terapia con } \\
\text { corticoesteroides }\end{array}$ & $\begin{array}{l}\text { Infección } \\
\text { fúngica } \\
\text { diseminada }\end{array}$ & $\begin{array}{l}\text { Bipolaris } \\
\text { spicifera }\end{array}$ & $\begin{array}{l}\text { Piel, pulmones, } \\
\text { corazón, tiroi- } \\
\text { des, riñones, } \\
\text { gl. suprarenal, } \\
\text { cerebro }\end{array}$ & $\begin{array}{l}\text { Biopsia piel: histopa- } \\
\text { tología + cultivos. } \\
\text { Biopsias post- } \\
\text { mortem }\end{array}$ & $A B L+I T R$ & $\begin{array}{l}\text { AM 0,25, } \\
\text { ITR 0,03 }\end{array}$ & Fallece & (26) \\
\hline $\begin{array}{l}\text { Sanatorio } \\
\text { Anchorena, } \\
\text { Buenos Aires, } \\
\text { Argentina, } \\
2003\end{array}$ & 3 años, $F$ & $\begin{array}{l}\text { Falla renal crónica } \\
\text { por síndrome } \\
\text { hemolítico urémi- } \\
\text { co, peritonitis por } \\
\text { Pseudomonas sp. }\end{array}$ & $\begin{array}{l}\text { Peritonitis } \\
\text { fúngica }\end{array}$ & $\begin{array}{l}\text { Bipolaris } \\
\text { spicifera }\end{array}$ & Peritonitis & $\begin{array}{l}\text { Líquido peritoneal } \\
\text { y secreciones del } \\
\text { catéter peritoneal: } \\
\text { microscopia }\end{array}$ & $\begin{array}{l}\text { FLC oral diario } \\
\text { por } 2 \text { sema- } \\
\text { nas }\end{array}$ & $\begin{array}{l}\text { No } \\
\text { reportado }\end{array}$ & $\begin{array}{l}\text { Sobrevive, } \\
\text { asintomática } \\
\text { a los } 6 \text { meses }\end{array}$ & (17) \\
\hline $\begin{array}{l}\text { Johns Hopkins } \\
\text { Hospital, } \\
\text { Baltimore, } \\
\text { USA, } 2003\end{array}$ & $\begin{array}{c}5 \text { años, } \\
\mathrm{M}\end{array}$ & $\begin{array}{l}\text { Leucemia } \\
\text { linfoblástica } \\
\text { aguda, } \\
\text { quimioterapia }\end{array}$ & $\begin{array}{l}\text { Infección } \\
\text { cutánea }\end{array}$ & $\begin{array}{l}\text { Bipolaris } \\
\text { spicifera }\end{array}$ & $\begin{array}{l}\text { Piel, mejilla } \\
\text { izquierda }\end{array}$ & $\begin{array}{l}\text { Biopsia excisional: } \\
\text { microscopia }+ \\
\text { histopatología }+ \\
\text { cultivos }\end{array}$ & $\begin{array}{l}\text { AMB } 30 \text { días, } \\
\text { luego ITR } \\
\text { profilaxis }\end{array}$ & $\begin{array}{l}\text { No } \\
\text { reportado }\end{array}$ & Sobrevive & (16) \\
\hline $\begin{array}{l}\text { Children's } \\
\text { Hospital Medical } \\
\text { Center, } \\
\text { Cincinnati, Ohio, } \\
\text { E.U.A, } 2014\end{array}$ & 20 meses & $\begin{array}{l}\text { Trasplante cardíaco } \\
\text { por hipoplasia de } \\
\text { corazón izquierdo, } \\
\text { rechazo crónico, } \\
\text { inmunosupresión }\end{array}$ & $\begin{array}{l}\text { Infección } \\
\text { fúngica } \\
\text { diseminada }\end{array}$ & $\begin{array}{l}\text { Bipolaris } \\
\text { spicifera }\end{array}$ & $\begin{array}{l}\text { Piel, SNC re- } \\
\text { gión periventri- } \\
\text { cular derecha }\end{array}$ & $\begin{array}{l}\text { Biopsia piel: micros- } \\
\text { copia + histopatolo- } \\
\text { gía + cultivos }\end{array}$ & $\begin{array}{l}\text { AM (no espe- } \\
\text { cificado) }\end{array}$ & $\begin{array}{l}\text { No } \\
\text { reportado }\end{array}$ & Fallece & (25) \\
\hline $\begin{array}{l}\text { Lok Nayak } \\
\text { Hospital, } \\
\text { New Delhi, } \\
\text { India, } 2015\end{array}$ & $\begin{array}{c}7 \text { años, } \\
\text { M }\end{array}$ & $\begin{array}{l}\text { Hidronefrosis bilate- } \\
\text { ral por obstrucción } \\
\text { de la unión uretero- } \\
\text { pélvica bilateral }\end{array}$ & $\begin{array}{l}\text { Feohifomicosis } \\
\text { renal unilateral }\end{array}$ & $\begin{array}{l}\text { Bipolaris } \\
\text { spicifera }\end{array}$ & Riñón izquierdo & $\begin{array}{l}\text { Biopsia renal: mi- } \\
\text { croscopia + histopa- } \\
\text { tología + cultivos }\end{array}$ & $\begin{array}{c}\mathrm{ABL}+\mathrm{ITR} 8 \\
\text { semanas }\end{array}$ & $\begin{array}{l}\text { No } \\
\text { reportado }\end{array}$ & $\begin{array}{l}\text { Sobrevive, } \\
\text { asintomático } \\
2 \text { meses }\end{array}$ & (34) \\
\hline $\begin{array}{l}\text { HCUC, } \\
\text { Santiago, } \\
\text { Chile, } 2016\end{array}$ & $\begin{array}{l}7 \text { años, } \\
\text { M }\end{array}$ & $\begin{array}{l}\text { Leucemia } \\
\text { mieloide aguda, } \\
\text { rinitis alérgica }\end{array}$ & $\begin{array}{l}\text { Feohifomicosis } \\
\text { invasora nasal, } \\
\text { pansinusitis }\end{array}$ & $\begin{array}{l}\text { Curvularia } \\
\text { spicifera }\end{array}$ & Tabique nasal & $\begin{array}{c}\text { Biopsia tabique } \\
\text { nasal: microscopia } \\
+ \text { histopatología }+ \\
\text { cultivos }\end{array}$ & $\begin{array}{l}V R C+A B L \\
3 \text { semanas, } \\
\text { luego VRC }\end{array}$ & $\begin{array}{l}\text { AM 1,0, } \\
\text { POS } 0,25 \\
\text { VRC } 0,25\end{array}$ & $\begin{array}{l}\text { Sobrevive. Fa- } \\
\text { llece } 6 \text { meses } \\
\text { después de } \\
\text { complicación } \\
\text { de leucemia }\end{array}$ & $\begin{array}{l}\text { Actual } \\
\text { publi- } \\
\text { cación }\end{array}$ \\
\hline
\end{tabular}


su desarrollo era inicial, la producción de melanina que les da el color es variable y depende del tiempo de crecimiento que haya tenido el hongo en el tejido. En casos en que la pigmentación no es evidente con tinciones de hematoxilina-eosina o en los que no se logra distinguir claramente un hongo dematiáceo, se recomienda utilizar la tinción Fontana-Masson para demostrar y resaltar la melanina ${ }^{42}$. En este caso, esta tinción especial no fue utilizada en el estudio histopatológico, por lo que no es posible descartar un hongo pigmentado. Por otro lado, si es que la infección hubiese sido causada por Aspergillus $\mathrm{u}$ otro hongo hialino, este habría crecido en el cultivo. En este, únicamente se aisló un agente el cual se identificó microscópicamente como B. spicifera y posteriormente se identificó como Curvularia spp. en el estudio molecular dado el reciente cambio de taxonomía ${ }^{4}$. Finalmente se interpretó como una infección invasora por un hongo dematiáceo y se realizó el manejo de acuerdo al diagnóstico. Es importante enfatizar la necesidad de interpretar el contexto completo del paciente, sus factores de riesgo y la respuesta al tratamiento. En este caso, se trata de un paciente con evidente riesgo de infección oportunista y que tuvo una buena evolución al manejo realizado.
Agradecimientos. Al personal de los laboratorios de Microbiología e Histopatología de la Red de Salud UC Christus. A Fabiola Fernández, PhD en Micología, del Centro de Genómica y Bioinformática, Universidad Mayor. Al equipo médico de los departamentos de Hemato-Oncología y Otorrinolaringología de la Pontificia Universidad Católica de Chile.

\section{Resumen}

Existen pocos reportes de infecciones por hongos dematiáceos en pediatría. Comunicamos el caso de una infección fúngica invasora del tabique nasal en un niño con una leucemia mieloide aguda, que se presentó como una lesión costrosa dolorosa en el vestíbulo nasal. Se realizó desbridamiento quirúrgico precoz y recibió tratamiento antifúngico biasociado, lográndose resolución completa de las lesiones, sin diseminación ni recaídas. El cultivo y la RPC universal fueron compatibles con Curvularia spicifera. El manejo de estas infecciones fúngicas representa un desafío, considerando que la elección del agente antifúngico y la duración de la terapia no están completamente establecidas.

\section{Referencias bibliográficas}

1.- Revankar S G, Patterson J E, Sutton D A, Pullen R, Rinaldi M G. Disseminated phaeohyphomycosis: review of an emerging mycosis. Clin Infect Dis 2002; 34: 467-76.

2.- Rinaldi M G, Phillips P, Schwartz J G, Winn R E, Holt G R, Shagets F W, et al. Human Curvularia infections. Report of five cases and review of the literature. Diagn Microbiol Infect Dis 1987; 6: 27-39.

3.- Revankar S G, Sutton D A. Melanized fungi in human disease. Clin Microbiol Rev 2010; 23 : 884-928.

4.- Manamgoda D S, Cai L, McKenzie E H C, Crous P W, Madrid H, Chukeatirote E, et al. A phylogenetic and taxonomic re-evaluation of the Bipolaris-Cochliobolus-Curvularia Complex. Fungal Diversity 2012; 56: 131-44.

5.- Sivanesan A. Graminicolous species of Bipolaris, Curvularia, Drechslera, Exserohilum and their teleomorphs. Mycological Papers 1987; 158: 1-261.

6.- Manamgoda D S, Rossman A Y, Castlebury L A, Crous P W, Madrid H, Chukeatirote E, et al. The genus Bipolaris. Stud Mycol 2014; 79: 221-88.

7.- Revankar S G. Dematiaceous fungi. Mycoses 2007; 50: 91-101.

8.- Forster R K, Rebell G, Wilson L A. Dematiaceous fungal keratitis. Clinical isolates and management. Br J Ophthalmol 1975; 59: 372-6.
9.- McGinnis M R, Campbell G, Gourley W K, Lucia H L. Phaeohyphomycosis caused by Bipolaris spicifera: an informative case. Eur J Epidemiol 1992; 8: 383-6.

10.- Gourley D S, Whisman B A, Jorgensen N L, Martin M E, Reid M J. Allergic Bipolaris sinusitis: clinical and immunopathologic characteristics. J Allergy Clin Immunol 1990; 85: 583-91.

11.- Sobol S, Love R, Stutman H R, Pysher T J. Phaeohyphomycosis of the maxilloethmoid sinus caused by Drechslera spicifera: a new fungal pathogen. Laryngoscope 1984; 94: 6207.

12.- Frenkel L, Kuhls T L, Nitta K, Clancy M, Howard D H, Ward P, et al. Recurrent Bipolaris sinusitis following surgical and antifungal therapy. Pediatr Infect Dis J 1987; 6: 1130-2.

13.- Buzina W, Braun H, Schimpl K, Stammberger H. Bipolaris spicifera causes fungus balls of the sinuses and triggers polypoid chronic rhinosinusitis in an immunocompetent patient. $\mathrm{J}$ Clin Microbiol 2003; 41: 4885-7.

14.- Straka B F, Cooper P H, Body B A. Cutaneous Bipolaris spicifera infection. Arch Dermatol 1989; 125: 1383-6.

15.- Estes S A, Merz W G, Maxwell L G. Primary cutaneous phaeohyphomycosis caused by Drechslera spicifera. Arch Dermatol 1977; 113: 813-5.

16.- Bilu D, Movahedi-Lankarani S, Kazin R A, Shields C, Moresi M. Cutaneous Bipolaris infection in a neutropenic patient with acute lymphoblastic leukemia. J Cutan Med Surg 2004; 8: 446-9.

17.- Bava A J, Fayad A, Cespedes C, Sandoval M. Fungal peritonitis caused by Bipolaris spicifera. Med Mycol 2003; 41: 529-31.

18.- Adam R D, Paquin M L, Petersen E A, Saubolle M A, Rinaldi M G, Corcoran J G, et al. Phaeohyphomycosis caused by the fungal genera Bipolaris and Exserohilum. A report of 9 cases and review of the literature. Medicine (Baltimore) 1986; 65: 203-17.

19.- Ogden P E, Hurley D L, Cain P T. Fatal fungal endarteritis caused by Bipolaris spicifera following replacement of the aortic valve. Clin Infect Dis 1992; 14: 596-8.

20.- Filizzola M J, Martínez F, Rauf S J. Phaeohyphomicosis of the central nervous system in immunocompetent host: report of a case and review of the literature. Int J Infect Dis 2003; 7: 282-6.

21.- Rosow L, Jiang J X, Deuel T, Lechpammer M, Zamani A A, Milner D A, et al. Cerebral phaeohyphomycosis caused by Bipolaris spicifera after heart transplantation. Transpl Infect Dis 2011; 13: 419-23.

22.- Yoshimori R N, Moore R A, Itabashi H H, Fujikawa D G. Granulomatous encephalitis caused by Drechslera spificera. Am J Clin Pathol 1982; 77: 363-70.

23.- Latham R H. Bipolaris spicifera meningitis complicating a neurosurgical procedure. Scand J Infect Dis 2000; 32: 102-3.

24.- Karim M, Sheikh H, Alam M, Sheikh Y. 
Disseminated Bipolaris infection in an asthmatic patient: case report. Clin Infect Dis 1993; 17: 248-53.

25.- Teran C G, Downes K, Medows M. Fatal Bipolaris spicifera infection in an immunosuppressed child. Br Med J Case Rep 2014. doi:10.1136/bcr-2013-009703

26.- Moore M L, Collins G R, Hawk B J, Russell T S. Disseminated Bipolaris spicifera in a neonate. J Perinatol 2001; 21: 399-401.

27.- Fernández M, Noyola D E, Rossmann S N, Edwards M S. Cutaneous phaeohypomycosis caused by Curvularia lunata and a review of Curvularia infections in pediatrics. Pediatr Infect Dis J 1999; 18: 727-31.

28.- Bryan C S, Smith C W, Berg D E, Karp R B. Curvularia lunata endocarditis treated with terbinafine: case report. Clin Infect Dis 1993; 16: 30-2.

29.- Kaushik S, Ram J, Chakrabarty A, Dogra M R, Brar G S, Gupta A. Curvularia lunata endophthalmitis with secondary keratitis. Am J Ophthalmol 2001; 131: 140-2.

30.- Ben-Ami R, Lewis R E, Raad II, Kontoyiannis D P. Phaeohyphomycosis in a tertiary care cancer center. Clin Infect Dis 2009; 48: 103341.

31.- da Cunha K C, Sutton D A, Fothergill A W, Gene J, Cano J, Madrid H, et al. In vitro antifungal susceptibility and molecular identity of 99 clinical isolates of the opportunistic fungal genus Curvularia. Diagn Microbiol Infect Dis 2013; 76: 168-74.

32.- Chowdhary A, Meis J F, Guarro J, de Hoog G S, Kathuria S, Arendrup M C, et al. ESCMID and ECMM joint clinical guidelines for the diagnosis and management of systemic phaeohyphomycosis: diseases caused by black fungi. Clin Microbiol Infect 2014; 20 Suppl 3: 47-75.

33.- Safdar A. Curvularia-favorable response to oral itraconazole therapy in two patients with locally invasive phaeohyphomycosis. Clin Microbiol Infect 2003; 9: 1219-23.

34.- Guarro J, Akiti T, Horta R A, Morizot Leite-Filho L A, Gené J, Ferreira-Gomes S, et al. Mycotic keratitis due to Curvularia senegalensis and in vitro antifungal susceptibilies of Curvularia spp. J Clin Microbiol 1999; 37: 4170-3.

35.- Kaur R, Bala K. Unilateral renal phaeohyphomycosis due to Bipolaris spicifera in an immunocompetent child-rare case presentation and review of literature. Mycoses 2015; 58: 437-44.

36.- Vallabhaneni S, Purfield A E, Benedict K, Luvsansharav U, Lockhart S R, Pham $\mathrm{C} \mathrm{D}$, et al. Cardiothoracic surgical site phaeohyphomycosis caused by Bipolaris mould, multiple US states, 2008-2013: a clinical description. Med Mycol 2016; 54 318-21.

37.- De Hoog G, Guarro G, Gene J, Figueras M. Atlas of clinical fungi. 2nd ed. Utrecht, The Netherlands, Centraalbureau voor Schimmelcultures. 2001; pág 598.

38.- Carter E, Boudreaux C. Fatal cerebral phaeohyphomycosis due to Curvularia lunata in an immunocompetent patient. J Clin Microbiol 2004; 42: 5419-23.

39.- Alcorn J. On the genera Cochliobolus and Pseudocochliobolus. Mycotaxon 1983; 16: 353-79.

40.- Berbee M, Pirseyedi M, Hubbard S. Cochliobolus phylogenetics and the origin of known, highly virulent pathogens, inferred from ITS and glyceraldehyde-3-phosphate dehydrogenase gene sequences. Mycologia 1999; 91: 964-77.

41.- Garnica M, Nucci M, Queiroz-Telles F. Difficult mycoses of the skin: advances in the epidemiology and management of eumycetoma phaeohyphomycosis and chromoblastomycosis. Curr Opin Infect Dis 2009; 22: 559-63.

42.- Guarner J, Brandt M E. Histopathologic diagnosis of fungal infections in the $21 \mathrm{st}$ century. Clin Microbiol Rev 2011; 24: 247-80. 